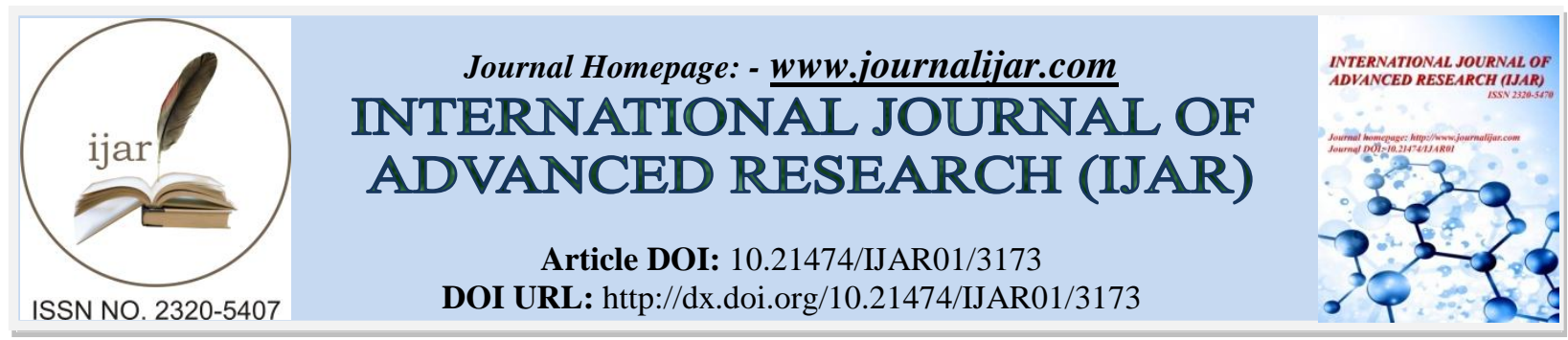

RESEARCH ARTICLE

\title{
THE PREDICTIVE VALUE OF HEPATIC ELASTOGRAPHY IN DIAGNOSIS OF HEPATIC FIBROSIS IN PATIENTS WITH CHRONIC HEPATITIS C VIRUS INFECTION.
}
Ahmed Hamouda Arnaout ${ }^{1}$, Hussein Mohammed Hussein ${ }^{1}$, Ahmed Abdel Aziz Elsammak ${ }^{2}$ and Ahmad Mohammad Ghandour ${ }^{43}$.
1. Department of Internal Medicine, Faculty of Medicine, Zagazig University, Egypt.
2. Department of Diagnostic Radiology, Faculty of Medicine, Zagazig University, Egypt.
3. Department of Radiology, Faculty of Medicine, Ain Shams University, Egypt.

\section{Manuscript Info}

-.......................

Manuscript History

Received: 20 December 2016

Final Accepted: 09 January 2017

Published: February 2017

Key words:-

Fibroscan, Diagnostic Test, Imaging, Chronic HCV.

\section{Abstract}

Introduction: Hepatic elastography (HE) is a noninvasive technique that measures liver stiffness and is used to diagnose hepatic fibrosis. It can help patients who are thought to have early-stage disease avoid a staging liver biopsy, but only when confounding variables that increase liver stiffness are excluded. Chronic inflammation from hepatitis $\mathrm{C}$ virus (HCV) infection is not considered to be one of these variables.

Aim of the study: To detect whether histologic and biochemical inflammation could confound the predictive value of hepatic elastography in patients with chronic hepatitis $\mathrm{C}$ virus infection.

Patients and methods: Study population included 68 patients with $\mathrm{HCV}$ and METAVIR fibrosis scores of $0-2$ in 288 patients with chronic liver disease, patients were $49.6 \pm 9.0$ years old, $64.3 \%$ were male, and they had an average body mass index of $26.7 \pm 4.1 \mathrm{~kg} / \mathrm{m}^{2}$.

Results: Inflammation (based on histologic analysis) and level of alanine aminotransferase

(ALT) were associated with liver stiffness. The chances of a patient having a level of stiffness that indicates cirrhosis increased with grade of inflammation and level of ALT. By using a conservative $14.5-\mathrm{kPa}$ cutoff for the diagnosis of cirrhosis, grade 3 inflammation had an odds ratio of 9.10 (95\% confidence interval, $2.49-33.4)$. Likewise, levels of ALT greater than 80 and $120 \mathrm{IU} / \mathrm{L}$ had odds ratios of 3.84 (95\% confidence interval, $2.10-7.00$ ) and 4.10 (95\% confidence interval, 2.18 -7.69), respectively. The effect of the level of ALT persisted when analysis was restricted to patients with fibrosis scores of F0 to F1.

Conclusions: Patients with HCV infection and early-stage fibrosis, increased levels of ALT correlate with liver stiffness among patients in the lowest stages of fibrosis (METAVIR scores 0-2). Patients without fibrosis but high levels of ALT could have liver stiffness within the range for cirrhosis. Inflammation should be considered a confounding variable in analysis of liver stiffness.

Copy Right, IJAR, 2017,. All rights reserved. 


\section{Introduction:-}

Hepatic elastography (HE) depends on ultrasound and shear waves to measure the liver stiffness. It is a validated and reproducible, noninvasive method for making the diagnosis of liver cirrhosis. At the opposite end of the fibrosis spectrum,

However, the predictive value of HE is a matter of ongoing study. Of chief interest for the practicing hepatologist is how chronic inflammation, as in the case of hepatitis $\mathrm{C}$, affects the predictive value of HE. It is already recognized that certain conditions intrinsic to liver pathophysiology such as acute hepatitis, sinusoidal congestion, and obstructive cholestasis increase liver stiffness independent of fibrosis stage (1).

Hepatic inflammation, when acute and severe, has an effect on the visco-elasticity of the liver and results in an overestimation of liver fibrosis stage by $\mathrm{HE}$, as is the case with hepatitis B flares and reappearance hepatitis $\mathrm{C}$ after liver transplantation $(2,3)$.

In the setting of smoldering inflammation (e.g., chronic hepatitis $\mathrm{C}$ or steatohepatitis), however, the impact of inflammation on the predictive value of HE is less certain. Liver stiffness measurements (LSMs) did not correlate with varying degrees of necro-inflammation in chronic hepatitis $\mathrm{C}$; likewise in steatohepatitis, there are reports of no correlation between LSM and necro-inflammatory activity or alanine aminotransferase (ALT) (4, 5). However, Oliveri et al concluded that necro-inflammation was independently associated with liver stiffness, even though in hepatitis B-infected individuals. There is sufficient animal model evidence that visco-elasticity of the hepatic parenchyma is decreased before the deposition of collagen scar (6), the etiology of this dynamic, physical property is poorly defined, although cellular edema and cyto-skeletal changes are possible contributors. Patients with advanced fibrosis (METAVIR F3-4) were excluded and focused specifically on the earliest stages of fibrosis (METAVIR F02) to determine whether histologic and biochemical inflammation confounds the predictive value of hepatic elastography.

\section{Patients and Methods:-}

This is a prospective study of liver stiffness by transient elastography (TE) in patients with chronic liver disease undergoing liver biopsy has been in place since 2009, with correlation of LSM to clinical data and histologic grade and stage of disease by METAVIR score. LSM was evaluated by using the FibroScan between December 2009 and September 2013. The total study population included men and women of at least 18 years of age with viral hepatitis.

Inclusion criteria: Patients with diagnosis of chronic hepatitis C (detectable serum HCV RNA), successful LSMs (kilopascals $[\mathrm{kPa}]$ ), and liver biopsy obtained within 3 months of each other.

Exclusion criteria: active malignancy, uninterpretable biopsy specimen, hepatitis C virus (HCV) therapy within last 6 months, other chronic liver disease (including Wilson's disease, alpha1-antitrypsin deficiency, cholestatic liver disease, or hemochromatosis), clinical ascites, body mass index (BMI) $\geq 40 \mathrm{~kg} / \mathrm{m}^{2}$, pregnancy, or an implantable cardiac device. The study was restricted to those patients with F0-F2 fibrosis. All patients provided written informed consent. Data collected were age, sex, BMI, stigmata of liver disease, ALT levels at the time of TE, and imaging results. Hepatitis B virus coinfection was ruled out by routine serology. LSMs (kPa) were determined as previously described. FibroScan was considered accurate if patients had at least 8 successful measurements, a minimum $60 \%$ success rate, and an interquartile range/median liver stiffness ratio of $<0.3$. The reproducibility of HE has been well-established in prior studies, with published intraoperator and interoperator agreement statistics of 0.98 (7). This finding is generalizable across studies that compare patients with the same underlying disease (8).

Intraoperator and interoperator variability was evaluated at one center. Measurements taken by 2 different people on the same day (interoperator) and measurements taken by the same person 1 week apart (intraoperator) had coefficients of variability of $2.97 \%$ and $5.37 \%$, respectively. Liver biopsies were obtained within 12 weeks of TE, and the METAVIR stage and grade were determined by one of two blinded, experienced hepatopathologists. The length of each liver biopsy specimen was established in centimeters. Fibrosis was staged according to METAVIR scoring system, a 0-4 scale: F0, no fibrosis; F1, portal fibrosis without septa; F2, portal fibrosis and few septa; F3, numerous septa or bridging fibrosis without cirrhosis; and F4, cirrhosis. Inflammatory activity was graded on a 0-3 score; 0 , none; 1 , mild; 2 , moderate; and 3, severe. Steatosis was categorized as grade $0(<5 \%)$, grade $1(5 \%-32 \%)$, grade $2(33 \%-65 \%)$, and grade $3(>66 \%)$ on H\&E staining. 
The number of patients who met inclusion criteria was 68 from a total number of 288 patients with available LSMs. The reason for exclusion from the study was a stage of fibrosis on biopsy of F3 or F4. The mean age of our study was $49.6 \pm 9.0$ years, with $64.3 \%$ men, and most patients had HCV genotype 4 infection $(90.8 \%)$. The average body mass index was $26.7 \pm 4.1 \mathrm{~kg} / \mathrm{m}^{2}$, which is considered overweight. The mean biopsy size was $1.74 \pm 0.6 \mathrm{~cm}$. Nine patients had stage F0 fibrosis (14.0\%), 32 had F1 (47\%), and 27 had F2 (39\%).

Two patients had grade 0 histologic inflammation (3\%), 38 had grade $1(57 \%)$, 26 had grade 2 (37\%), and 2 had grade 3 (3\%). $25.4 \%$ of patients had ALT < 40 IU/L, $45.6 \%$ of them had ALT between 40 and 80 IU/L, 14.4\% had ALT between 80 and $120 \mathrm{IU} / \mathrm{L}$, and $14.6 \%$ had ALT > $120 \mathrm{IU} / \mathrm{L} .43 .7 \%$ of patients had Steatosis and $7.2 \%$ of patients had diabetes (Table 1).

Table 1:- Basic characteristics of study population divided by METAVIR score. Age, grade of histologic inflammation, and liver stiffness differ significantly across stages of fibrosis.

\begin{tabular}{|c|c|c|c|c|}
\hline Total, $\mathrm{N}=68$ & F0 fibrosis $(\mathrm{n}=9)$ & F1 fibrosis $(\mathrm{n}=32)$ & F2 fibrosis $(\mathrm{n}=27)$ & P value \\
\hline Age (years) & $47.3 \pm 9.2$ & $49.1 \pm .1$ & $51.0 \pm 8.5$ & 0.001 \\
\hline Sex (Male; Female) & $5 ; 4$ & $21 ; 11$ & $18 ; 9$ & NS \\
\hline BMI (kg/m2) & $26.0 \pm 4.2$ & $26.6 \pm 4.1$ & $27.0 \pm 4.1$ & NS \\
\hline ALT (IU/L) & $62.9 \pm 44.11$ & $76.3 \pm 88.7$ & $82.0 \pm 65.2$ & NS \\
\hline Steatosis (yes; no) & $5 ; 4$ & $13 ; 19$ & $12 ; 15$ & NS \\
\hline $\begin{array}{c}\text { Grade of } \\
\text { inflammation }\end{array}$ & $1.04 \pm 0.48$ & $1.31 \pm 0.52$ & $1.62 \pm 0.54$ & $<0.001$ \\
\hline LSM $(\mathrm{kPa})$ & $7.2 \pm 7.1$ & $7.42 \pm 4.3$ & $9.2 \pm 7.4$ & 0.001 \\
\hline
\end{tabular}

The statistical analysis of the study was modified according to the nature of the variable. Patients' demographics given as mean \pm standard deviation. Table 2 showed that the grade of inflammation was transformed into a continuous variable, and ALT was represented in multiples of the upper limit of normal (ULN) (40 IU/L). Student $t$ testing for 2 variables with Normal distribution (Table 3), one-way analysis of variance with Scheffé method for multiple comparisons for more than 2 variables of normal distribution (Tables 1 and 3), regression techniques, and other descriptive statistics were performed. (Tables 2 and 4).

Table 2:- Effect of Inflammation on Odds of Falsely Significant LSMs in Patients with F0-F1 Fibrosis.

\begin{tabular}{|c|c|c|c|c|c|c|}
\hline & & $\begin{array}{l}\text { 9.5-kPa cut- } \\
\text { off for } \geq \mathrm{F} 3 \\
\text { fibrosis }\end{array}$ & $\begin{array}{c}\text { 10.3-kPa cut- } \\
\text { off } \\
\text { For } \geq \mathrm{F} 3 \\
\text { fibrosis } \\
\end{array}$ & $\begin{array}{l}\text { 11.9-kPa cut- } \\
\text { off } \\
\text { for cirrhosis }^{7}\end{array}$ & $\begin{array}{l}\text { 12.5-kPa cut- } \\
\text { off } \\
\text { for cirrhosis }\end{array}$ & $\begin{array}{l}\text { 14.5-kPa cut- } \\
\text { off } \\
\text { for cirrhosis }\end{array}$ \\
\hline & & OR $(95 \% \mathrm{CI})$ & OR $(95 \% \mathrm{CI})$ & OR $(95 \% \mathrm{CI})$ & OR $(95 \% \mathrm{CI})$ & OR $(95 \% \mathrm{CI})$ \\
\hline \multirow[t]{3}{*}{ ALT } & $\begin{array}{c}>\text { ULN }(40 \\
\text { IU/L) }\end{array}$ & $\begin{array}{c}2.46(1.24- \\
4.88) \\
\end{array}$ & $\begin{array}{c}2.22(1.08- \\
6.24) \\
\end{array}$ & $\begin{array}{c}2.34(0.95- \\
5.75) \\
\end{array}$ & $\begin{array}{c}2.34(0.88- \\
6.24) \\
\end{array}$ & $\begin{array}{c}2.41(0.69- \\
8.34) \\
\end{array}$ \\
\hline & $\begin{array}{c}>2 \times \mathrm{ULN} \\
(80 \mathrm{IU} / \mathrm{L})\end{array}$ & $\begin{array}{c}5.64(3.30- \\
9.59)\end{array}$ & $\begin{array}{c}3.25(1.83- \\
5.75)\end{array}$ & $\begin{array}{c}4.27(2.15- \\
8.49)\end{array}$ & $\begin{array}{c}3.76(1.80- \\
7.85)\end{array}$ & $\begin{array}{c}4.82(1.91- \\
12.15)\end{array}$ \\
\hline & $\begin{array}{l}>3 \times \text { ULN } \\
(120 \mathrm{IU} / \mathrm{L})\end{array}$ & $\begin{array}{c}3.90(2.01- \\
7.56)\end{array}$ & $\begin{array}{c}2.02(1.00- \\
4.10)\end{array}$ & $\begin{array}{c}2.42(1.17- \\
5.01)\end{array}$ & $\begin{array}{c}3.49(1.5- \\
8.10)\end{array}$ & $\begin{array}{c}3.62(1.32- \\
9.98)\end{array}$ \\
\hline
\end{tabular}

\section{Results:-}

Controlling for stage of fibrosis, the most significant associations with liver stiffness was in grade of histologic inflammation and ALT levels. First a univariate analysis with a number of variables that could possibly impact liver stiffness. There were 4 significant relationships: grade 3 histologic inflammation (beta 9.68, P = 6.96E-07), ALT expressed as a multiple of ULN (beta $0.76, \mathrm{P}=5.30 \mathrm{E}-10)$, gender (beta $0.072, \mathrm{P}=0.003$ ), and BMI (beta $0.19, \mathrm{P}=$ 0 .0009). Age, Steatosis, and diabetes did not significantly impact liver stiffness. From then, by using the variables found to be significantly associated with liver stiffness by univariate analysis, and by using multiple linear regression analysis, again controlling for fibrosis. Here, only grade 3 histologic inflammation (beta 9.07, $\mathrm{P}=1.15 \mathrm{E}-$ 06) and ALT expressed as a multiple of ULN (beta 0.69, P = 1.85E-08) were significant.

Because of the association of inflammation with liver stiffness, we examined the effect of inflammation on the false positive staging of patients in whom elastography suggested advanced fibrosis (METAVIR F3-4), as defined by 
criteria set forth by Castera et al, ${ }^{4}$ Fraquelli et al, ${ }^{7}$ and Ziol et al. ${ }^{9}$ Among these, the lowest cutoff for F3 was from Castera et al $(9.5 \mathrm{kPa})$.

The proportion of our patients who met these criteria by ALT was as follows: 12.0\% (ALT < 40 IU/L), 15.2\% (ALT $<80 \mathrm{IU} / \mathrm{L}), 17.8 \%$ (ALT < $120 \mathrm{IU} / \mathrm{L}$ ), and 44.8\% (ALT > $120 \mathrm{IU} / \mathrm{L})$. As the grade of inflammation or ALT level increased, an increasing proportion of patients received false-positive stiffness measurements. Although the greatest effect of histologic inflammation appeared to occur at grade 3, the effect of inflammation measured by ALT appeared to be linear.

When the analysis is restricted to patients with F0-F1 only, many patients met elastographic criteria for significant fibrosis.

Many still met criteria for cirrhosis. Although no more than 5.2\% of patients with ALT < 40 IU/L met any of the criteria for cirrhosis, of the patients with ALT $>120 \mathrm{IU} / \mathrm{L}, 26.1 \%$ were cirrhotic by the criteria of Fraquelli et al ${ }^{7}$ $(11.9 \mathrm{kPa}), 19.6 \%$ by those of Castera et al ${ }^{4}(12.5 \mathrm{kPa})$, and $13.0 \%$ by those of Ziol et al ${ }^{9}(14.5 \mathrm{kPa})$. Many more met the criteria of Castera et al for F3 (9.5 kPa): 9.5\% (ALT < $40 \mathrm{IU} / \mathrm{L}$ ), $11.5 \%$ (ALT < $80 \mathrm{IU} / \mathrm{L}$ ), $17.1 \%$ (ALT < $120 \mathrm{IU} / \mathrm{L})$, and $39.1 \%$ (ALT > $120 \mathrm{IU} / \mathrm{L})$.

Table 3:- Association of Study Variables with Liver Stiffness

\begin{tabular}{|c|c|c|c|c|c|c|}
\hline \multirow{2}{*}{ Variable } & \multicolumn{3}{|c|}{ Univariate linear regression } & \multicolumn{3}{c|}{ Multivariate linear regression } \\
\cline { 2 - 7 } & $\beta$ & Standard error & P value & $\beta$ & Standard error & P value \\
\hline $\begin{array}{l}\text { Grade of } \\
\text { inflammation }\end{array}$ & \multicolumn{7}{|l|}{} \\
\hline Grade 1 & 1.45 & 1.58 & 0.36 & & & \\
\hline Grade 2 & 0.52 & 0.48 & 0.28 & & & \\
\hline Grade 3 & 9.68 & 1.93 & $6.96 \mathrm{E}-07$ & 9.07 & 1.85 & $1.15 \mathrm{E}-06$ \\
\hline ALT (x ULN) & 0.76 & 0.12 & $5.30 \mathrm{E}-10$ & 0.69 & 0.12 & $1.85 \mathrm{E}-08$ \\
\hline Steatosis (yes/no) & 0.41 & 0.13 & 0.18 & & & \\
\hline Age (per year) & 0.04 & 0.026 & 0.09 & & & NS \\
\hline Gender & 0.072 & 0.24 & 0.003 & & & NS \\
\hline BMI (kg/m2) & 0.19 & 0.06 & 0.0009 & & & \\
\hline $\begin{array}{c}\text { Diagnosis of } \\
\text { diabetes (yes/no) }\end{array}$ & 0.84 & 0.47 & 0.08 & & & \\
\hline
\end{tabular}

Table 4 shows the odds of inflammation causing patients with F0-F2 fibrosis to receive LSMs that meet cutoffs for $>$ F3 and > F4 fibrosis by elastography. Castera et al ${ }^{4}$ concluded that effective cutoffs to diagnose F3 and F4 fibrosis are $9.5 \mathrm{kPa}$ and $12.5 \mathrm{kPa}$, respectively. Fraquelli et al ${ }^{7}$ used cutoffs of 10.3 and $11.9 \mathrm{kPa}$ for F3 and F4 fibrosis, respectively. Finally, Ziol et al ${ }^{9}$ used a $14.5-\mathrm{kPa}$ cutoff for F4 fibrosis. For this analysis, variables were chosen according to their statistical significance in the multivariate regression: grade of necroinflammation and ALT as a multiple of its ULN (40 IU/L).

The effect of histologic inflammation on the odds of a false-positive measurement by elastography (Table 4) was first examined. By comparing the proportion of patients in each grade of histologic inflammation that met the above criteria for advanced fibrosis, we determined the odds ratio (OR) for obtaining a falsely significant result as a function of inflammation.

We repeated this analysis for the effect of histologic inflammation restricted to those patients with F0-1 fibrosis. In this restricted stage of fibrosis, there were some patients with grade 2 inflammation and fewer patients with grade 3 inflammation.

The effect of inflammation as reflected by the ALT level was examined. There was a significant effect of ALT on elastography, whether the data were analyzed by using patients with F0-2 (Table 4) or only F0-1 fibrosis (Table 2). ALT levels > $40 \mathrm{IU} / \mathrm{L}$ (ULN) exhibited a trend toward a significant effect for patients with F0-2 (OR, 1.51-1.71 with CIs that cross 1) but significantly increased the odds that a patient's LSM would meet criteria for F3 fibrosis for patients with F0-1 (OR, 2.46; 95\% CI, $1.24-4.88$ for 9.5-kPa cutoff and OR, 2.22; 95\% CI, $1.08-6.24$ for 
10.3-kPa cutoff). For ALT levels > 80 and $>120 \mathrm{IU} / \mathrm{L}$, there was a reliable, sizable effect on false-positive LSM results, irrespective of the inclusion of F2 patients (Tables 2 and 4).

Table 4:- Effect of Inflammation on Odds of Falsely Significant LSMs in Patients with F0-F2 Fibrosis

\begin{tabular}{|c|c|c|c|c|c|c|}
\hline & $\begin{array}{c}\text { 9.5-kPa cut- } \\
\text { off for } \geq \mathrm{F3} \\
\text { fibrosis }\end{array}$ & $\begin{array}{c}\text { 10.3-kPa cut- } \\
\text { off } \\
\text { For } \geq \mathrm{F3} \\
\text { fibrosis }^{7}\end{array}$ & $\begin{array}{l}\text { 11.9-kPa cut- } \\
\text { off } \\
\text { for cirrhosis }\end{array}$ & $\begin{array}{l}\text { 12.5-kPa cut- } \\
\text { off } \\
\text { for cirrhosis }\end{array}$ & $\begin{array}{l}\text { 14.5-kPa cut- } \\
\text { off } \\
\text { for cirrhosis }\end{array}$ \\
\hline & & OR $(95 \% \mathrm{CI})$ & OR $(95 \% \mathrm{CI})$ & OR $(95 \% \mathrm{CI})$ & OR $(95 \% \mathrm{CI})$ & OR $(95 \% \mathrm{CI})$ \\
\hline \multirow[t]{3}{*}{ ALT } & $\begin{array}{c}>\text { ULN (40 } \\
\text { IU/L) }\end{array}$ & $\begin{array}{c}1.51(0.86- \\
2.62)\end{array}$ & $\begin{array}{c}1.60(0.88- \\
2.84)\end{array}$ & $\begin{array}{c}1.60(0.73- \\
3.5)\end{array}$ & $\begin{array}{c}1.62(0.71- \\
3.71)\end{array}$ & $\begin{array}{c}1.71(0.61- \\
4.78)\end{array}$ \\
\hline & $\begin{array}{c}>2 \times \text { ULN } \\
(80 \mathrm{IU} / \mathrm{L})\end{array}$ & $\begin{array}{c}3.37(2.29- \\
4.97)\end{array}$ & $\begin{array}{c}2.94(1.96- \\
4.40)\end{array}$ & $\begin{array}{c}3.70(2.27- \\
6.02)\end{array}$ & $\begin{array}{l}3.49(2.1- \\
5.81)\end{array}$ & $\begin{array}{c}3.84(2.10- \\
7.00)\end{array}$ \\
\hline & $\begin{array}{l}>3 \times \text { ULN } \\
(120 \mathrm{IU} / \mathrm{L})\end{array}$ & $\begin{array}{c}3.75(2.37- \\
5.92)\end{array}$ & $\begin{array}{c}2.92(1.81- \\
4.67)\end{array}$ & $\begin{array}{c}4.01(2.36- \\
6.82)\end{array}$ & $\begin{array}{c}3.83(2.20- \\
6.66)\end{array}$ & $\begin{array}{c}4.09(2.18- \\
7.69)\end{array}$ \\
\hline \multirow[t]{3}{*}{$\begin{array}{c}\text { Grade of } \\
\text { inflammation }\end{array}$} & $\geq$ Grade 1 & $\begin{array}{c}4.27(0.56- \\
32.5)\end{array}$ & $\begin{array}{c}3.52(0.46- \\
26.9) \\
\end{array}$ & $\begin{array}{c}2.03(0.27- \\
15.7)\end{array}$ & $\begin{array}{c}1.81(0.24- \\
13.9) \\
\end{array}$ & $\begin{array}{c}1.19(0.15- \\
9.2)\end{array}$ \\
\hline & $\geq$ Grade 2 & $\begin{array}{c}1.88(1.33- \\
2.72) \\
\end{array}$ & $\begin{array}{c}1.84(1.25- \\
2.71) \\
\end{array}$ & $\begin{array}{c}1.53(0.96- \\
2.40) \\
\end{array}$ & $\begin{array}{c}1.51(0.93- \\
2.46)\end{array}$ & $\begin{array}{c}1.18(0.66- \\
2.11)\end{array}$ \\
\hline & Grade 3 & $\begin{array}{c}3.68(1.05- \\
12.9)\end{array}$ & $\begin{array}{c}4.48(1.28- \\
15.4)\end{array}$ & $\begin{array}{c}7.87(2.23- \\
27.8)\end{array}$ & $\begin{array}{c}5.85(1.61- \\
21.2)\end{array}$ & $\begin{array}{c}9.10(2.48- \\
33.4)\end{array}$ \\
\hline
\end{tabular}

\section{Discussion:-}

In this study of patients with chronic hepatitis $\mathrm{C}$ and early fibrosis, we showed that inflammation increases liver stiffness.

For a large number of patients with F0-F2 fibrosis, inflammation significantly increased the odds of receiving a liver stiffness score indicative of advanced fibrosis and cirrhosis. TE is generally accepted for its ability to diagnose cirrhosis and exclude clinically significant fibrosis in published data on studies with hepatitis $C(4,7$ and 9$)$. There is ongoing open discussion about the interpretation of TE in clinical practice, particularly because of the confounders intrinsic to acute and chronic liver disease that might also increase liver stiffness. The variable with the most conflicting evidence to date is the presence of chronic inflammation, as in the case of hepatitis C and NASH $(4,5,10$ and12).

Our results provide further evidence for a viscoelastic property of the liver that is influenced by conditions other than fibrosis, similar to that observed in cases of acute flares of hepatitis B or the reappearance of hepatitis $\mathrm{C}$ after orthotopic liver transplantation. A potential mechanism is that parenchymal edema increases stiffness in the absence of fibrosis and is responsible for the dramatic shift of stiffness seen with acute inflammation. Because more than one-half of liver biopsies are performed for the staging of chronic hepatitis $\mathrm{C}$, it is necessary that the hepatologist understands how to interpret elastography findings in the presence of chronic inflammation.

Our study showed the following findings: First, we showed that some patients with chronic hepatitis C and F0-F2 fibrosis are being read as cirrhotic on TE. This includes $40 \%-50 \%$ of patients with grade 3 histologic inflammation and $18.8 \%-28.1 \%$ of patients with ALT levels $>120 \mathrm{IU} / \mathrm{L}$, depending on the stiffness cutoff used. Second, by multiple regression, we showed that the only variables with a significant impact on liver stiffness aside from fibrosis are markers of inflammation (ALT and histologic grade). Third, we quantified the effect of inflammation with the odds that a given ALT or grade of inflammation will cause a reading of F3 or F4 fibrosis. Fourth, we found that when we restrict our analysis to only the lowest stages of fibrosis (F0 -F1); the effect of grade of inflammation is not measurable, whereas the effect of ALT level remains strong. In summary, chronic necroinflammation, best reflected by ALT, can lead to an overestimation of liver fibrosis by HE.

We chose to isolate the earliest stages of fibrosis for 2 reasons: (1) it is at the opposite end of fibrosis spectrum (stage F4) where the positive predictive value of elastography is already considered reliable and where the relative contribution of inflammation is overwhelmed by the effect of total collagen and scar, and (2) the decision to avoid a staging liver biopsy (in any case other than cirrhosis) very much depends on predictive values at the lowest stages of 
fibrosis. In an aim to assessment and prioritizing of patients for the decision-making for liver biopsy, it has been suggested that elastography measurements in the cirrhotic range (>12.5 or $14.5 \mathrm{kPa})$ do not need biopsy, and results in the intermediate ranges (between 7.3 and $12.5 \mathrm{kPa}$, for example) would need biopsy only if a specific stage of fibrosis is desired to make treatment decisions (1). Our study evaluates the diagnostic implications at the lowest stages of liver fibrosis.

It was shown that stiffness increased during flares of hepatitis (2 and 13) and acute hepatitis (10) and decreases after virologic response to treatment (14). Others found that higher ALT for a given METAVIR score correlated with higher stiffness (10,12 and 15). Conversely, a meta-analysis supports the accuracy of HE across many disease types even in the presence of inflammation (16) However, none of the above studies focused solely on early-stage fibrosis in hepatitis $\mathrm{C}$.

Castera et al ${ }^{4}$ in 2005 showed that in 183 patients with hepatitis C and F1-F4 fibrosis, the effect of necroinflammation on stiffness is negligible when controlling for fibrosis in a multiple regression. Our data from 68 patients with hepatitis $\mathrm{C}$ and F0-F2 fibrosis suggested an association between LSM and both histologic and biochemical measures of necroinflammation. This difference with our data is best explained by the fact that Castera et al had 0 patients with F0 fibrosis and 100 patients with F1-F2 in their study.

The utility of our findings should be evaluated in a context where minimal fibrosis is proportionate with HE reading of $\mathrm{kPa}<5.5$ or $\mathrm{kPa}<7.3 \mathrm{kPa}$. Our data strengthen the negative predictive value of widely held criteria, while weakening the positive predictive value of measurements that fall within an intermediate and advanced range. This interpretation is a reflection of the potential viscoelastic alterations caused by a chronic inflammatory state of the liver. We conclude that for chronic hepatitis $\mathrm{C}$, TE readings $<7.3 \mathrm{kPa}$ should be regarded as accurate for excluding F3-4 fibrosis regardless of the grade of inflammation. Elastographic results in the intermediate range (between 7.3 and $13 \mathrm{kPa}$ ) should be interpreted with caution, and ALT > $2 \times \mathrm{ULN}$ is more likely to exert this confounding influence. An alternative to biopsy in such cases is to use noninvasive serologic markers of fibrosis, because concordance would add predictive value.

So the grade of histologic and laboratory-based inflammation seen in chronic hepatitis $\mathrm{C}$ is positively correlated with liver stiffness at the lowest stages of fibrosis $(\mathrm{F} 0-\mathrm{F} 2)$. As a result, the predictive value of TE is compromised when intermediate and advanced scores $(\mathrm{kPa})$ are obtained but strengthened when low scores are obtained. This might lead the hepatologist to consider many more patients for therapeutic intervention or liver biopsy, when in reality they have a clinically less significant stage of fibrosis. The hepatologist should recognize this limitation and account for chronic inflammation when interpreting TE results.

\section{Recommendation:-}

Future studies could look specifically at combining patients with early-stage fibrosis and divergent elastographic measurements with a noninvasive serologic panel of fibrosis markers. This "second opinion" might provide more confidence in differentiating the true-positive from the false-positive result.

\section{References:-}

1. Cohen EB, Afdhal NH. Ultrasound-based hepatic elastography: origins, limitations, and applications. J Clin Gastroenterol 2010; 44:637-645.

2. Oliveri F, Coco B, Ciccorossi P, et al. Liver stiffness in the hepatitis B virus carrier: a non-invasive marker of liver disease influenced by the pattern of transaminases. World J Gastroenterol 2008; 14:6154-6162.

3. Sagir A, Erhardt A, Schmitt M, et al. Transient elastography is unreliable for detection of cirrhosis in patients with acute liver damage. Hepatology 2008; 47: 592-595.

4. Castéra L, Vergniol J, Foucher J, et al. Prospective comparison of transient elastography, Fibrotest, APRI, and liver biopsy for the assessment of fibrosis in chronic hepatitis C. Gastroenterology 2005;128:343-350.

5. Wong VW, Vergniol J, Wong GL, et al. Diagnosis of fibrosis and cirrhosis using liver stiffness measurement in nonalcoholic fatty liver disease. Hepatology 2010; 51:454-462.

6. Georges PC, Hui JJ, Gombos Z, et al. Increased stiffness of the rat liver precedes matrix deposition: implications for fibrosis. Am J Physiol Gastrointest Liver Physiol 2007; 293:G1147-G1154.

7. Fraquelli M, Rigamonti C, Casazza G, et al. Reproducibility of transient elastography in the evaluation of liver fibrosis in patients with chronic liver disease. Gut 2007; 56:968-973. 
8. Friedrich-Rust M, Ong MF, Martens S, et al. Performance of transient elastography for the staging of liver fibrosis: a meta-analysis. Gastroenterology 2008; 134:960-974.

9. Ziol M, Handra-Luca A, Kettaneh A, et al. Noninvasive assessment of liver fibrosis by measurement of stiffness in patients with chronic hepatitis C. Hepatology 2005; 41:48-54.

10. Arena U, Vizzutti F, Corti G, et al. Acute viral hepatitis increases liver stiffness values measured by transient elastography. Hepatology 2008; 47:380-384.

11. Kirk GD, Astemborski J, Mehta SH, et al. Assessment of liver fibrosis by transient elastography in persons with hepatitis C virus infection or HIV-hepatitis C virus coinfection. Clin Infect Dis 2009; 48:963-972.

12. Nitta $\mathrm{Y}$, Kawabe N, Hashimoto S, et al. Liver stiffness measured by transient elastography correlates with fibrosis area in liver biopsy in patients with chronic hepatitis C. Hepatol Res 2009; 39:675-684.

13. Coco B, Oliveri F, Maina AM, et al. Transient elastography: a new surrogate marker of liver fibrosis influenced by major changes of transaminases. J Viral Hepat 2007; 14:360-369.

14. Vergniol J, Foucher J, Castéra L, et al. Changes of non-invasive markers and FibroScan values during HCV treatment. J Viral Hepat 2009; 16:132-140.

15. Wong GL, Wong VW, Choi PC, et al. Assessment of fibrosis by transient elastography compared with liver biopsy and morphometry in chronic liver diseases. Clin Gastroenterol Hepatol 2008; 6:1027-1035.

16. Talwalkar JA, Kurtz DM, Schoenleber SJ, et al. Ultrasound-based transient elastography for the detection of hepatic fibrosis: systematic review and meta-analysis. Clin Gastroenterol Hepatol 2007; 5:1214-1220. 